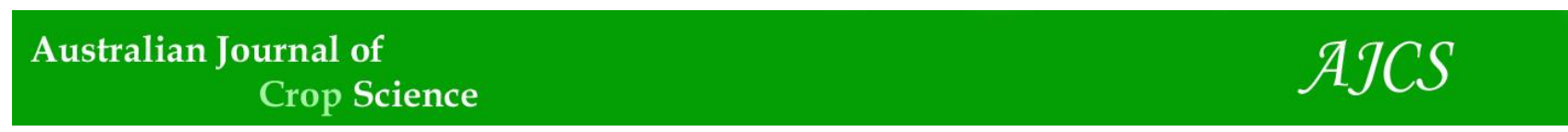

AJCS 10(10):1455-1459 (2016)

ISSN:1835-2707

DOI: $10.21475 /$ ajcs.2016.10.10.p7670

\title{
Effect of tobacco leaf width/length ratio on tobacco quality: a case study in the Chongqing tobacco production area
}

\author{
Jiang Hou-long ${ }^{1}$, Xu Chen ${ }^{1, *}$, Wang Dai-bin ${ }^{1}$, Gen Li-na ${ }^{1}$, Zhao Ming ${ }^{1}$, Zhu Xiao-wei ${ }^{2}$ \\ ${ }^{1}$ Chongqing Tobacco Science Research Institute, Chongqing 400715, China \\ ${ }^{2}$ Chongqing Tobacco Company, Chongqing 400020, China
}

*Corresponding author: cqxuchen@139.com; jhl513@163.com

\begin{abstract}
This study aimed at investigating the effect of the width/length ratio of flue-cured tobacco leaves on their chemical composition and neutral aroma components. Yunyan 87 was selected as the raw material, and four treatment conditions were designed for the middle and upper leaves. All research was conducted in the city of Chongqing in southwest China. Results indicated that correlations between the width/length ratio and the contents of total sugar, reducing sugar, and potassium, the difference between total and reducing sugar contents, the ratio of sugar to nicotine, and the ratio of potassium to chlorine were significantly positive in the upper and middle leaves. By contrast, correlations with the contents of nicotine and chlorine and the ratio of reducing to total sugar were significantly negative. In addition, the contents of phenylalanines, Maillard reaction products, carotenoids, neophytadiene, and neutral aroma components were higher in the leaves with larger width/length ratios. Therefore, appropriate measures should be implemented to increase the width/length ratio of the upper and middle leaves of tobacco to achieve improvements in tobacco quality.
\end{abstract}

Keywords: Chongqing; Flue-cured tobacco; Width/length ratio; Chemical composition; Neutral aroma components. Abbreviations: RS, Reducing sugar; TS, Total sugar; Nic, nicotine; $\mathrm{Cl}$, chlorine; $\mathrm{K}$, potassium.

\section{Introduction}

Tobacco is an important commercial crop in China. The quality of tobacco leaves depends on the breed as well as the cultivation and ecological conditions (Zuo, 1993; Xu et al., 2005). The physical characteristics of tobacco leaves are critical determinants of tobacco leaf quality and processability. These leaves directly affect the economic value of tobacco leaves (Zhou et al., 1996; Yan et al., 2001). The most important physical features of the tobacco leaf are its length and width. The length of a leaf is the straight-line distance from the main vein's base to the leaf apex. This characteristic is an important index for the classification of leaves and evaluation of appearance quality (Cheng et al., 2007). When classifying leaves, leaf length can be artificially controlled to keep it within a standard range. Leaf width is represented by the largest width of a leaf. Although this property is an essential index for measuring the state of leaf development and industrial usability, it is always ignored in leaf classification schemes. It is common for width differences among leaves to be a significant determinant in tobacco purchase even when their lengths are nearly the same. Furthermore, leaf width can exert significant effects on the processing and industrial usability of tobacco. Therefore, the ratio of width to length (width/length ratio) of tobacco leaf of the same grade has been proposed for use in evaluating the appearance quality of leaves for accurate evaluation of leaf development state and industrial usability. Here, we used the variety "Yunyan 87" from the Chongqing tobacco production area to conduct an in-depth analysis of the relationship between leaf width/length ratio and chemical composition, coordination of chemical composition, and neutral aroma components of tobacco leaves. The results provide an important theoretical basis for improving tobacco cultivation techniques.

Results

Effects of leaf width/length ratio on the chemical composition of tobacco leaves

Chemical ingredients comprise an important factor that affects the inherent quality of flue-cured tobacco (Zuo, 1993). The contents of five chemical ingredients, including reducing sugar, total sugar, nicotine, potassium, and chlorine in tobacco leaves with different width/length ratios were investigated in this study (Table 1). Table 1 shows that leaf width/length ratio exerted a highly significant effect on the content of chemical ingredients in upper and middle tobacco leaves. With increase in leaf width/length ratio, a highly significant increase in sugar content was observed. Conversely, nicotine content showed a highly significant decrease. The correlation of leaf width/length ratio to the chlorine contents of upper and middle leaves was negative, whereas the correlation with potassium content was positive.

According to the standard of chemical composition of "international standard tobacco leaves" (Chen et al., 2004), the total sugar content of upper and middle leaves as well as the content of reducing sugar of middle leaves were higher, whereas the reducing sugar content of the upper leaves and the content of nicotine of middle leaves were all at the middle level The nicotine content of the upper leaves exhibited a negative correlation with the width/length ratio. In addition, as leaf width/length ratio increased, the content of potassium tended to 
Table 1. Effects of different leaf width/length ratio on chemical components of flue-cured tobacco, and the correlation between leaf width/length ration and Rs, TS, Nic., Cl, K.

\begin{tabular}{|c|c|c|c|c|c|c|}
\hline Treatmen & & $\mathrm{RS}^{\#}$ & $\mathrm{TS}^{\S}$ & Nic. ${ }^{\phi}$ & $\mathrm{Cl}^{*}$ & $\mathrm{~K}^{\Pi}$ \\
\hline \multirow{5}{*}{$\begin{array}{l}\text { Middle } \\
\text { leaf }\end{array}$} & $\mathrm{T} 1$ & $23.123 \pm 0.096 \mathrm{~A}$ & $29.068 \pm 0.068 \mathrm{~A}$ & $2.951 \pm 0.051 \mathrm{C}$ & $0.234 \pm 0.009 \mathrm{C}$ & $1.869 \pm 0.006 \mathrm{~A}$ \\
\hline & $\mathrm{T} 2$ & $25.865 \pm 0.068 \mathrm{~B}$ & $32.112 \pm 0.009 \mathrm{~B}$ & $2.922 \pm 0.010 \mathrm{C}$ & $0.212 \pm 0.012 \mathrm{~B}$ & $1.846 \pm 0.024 \mathrm{~A}$ \\
\hline & $\mathrm{T} 3$ & $26.242 \pm 0.059 \mathrm{C}$ & $33.653 \pm 0.057 \mathrm{C}$ & $2.780 \pm 0.023 \mathrm{~B}$ & $0.211 \pm 0.002 \mathrm{~B}$ & $1.944 \pm 0.014 \mathrm{~B}$ \\
\hline & $\mathrm{T} 4$ & $27.101 \pm 0.010 \mathrm{D}$ & $34.533 \pm 0.115 \mathrm{D}$ & $2.453 \pm 0.023 \mathrm{~A}$ & $0.197 \pm 0.002 \mathrm{~A}$ & $2.160 \pm 0.020 \mathrm{C}$ \\
\hline & leaf width/length ratio & 0.924 & $0.964^{*}$ & -0.925 & -0.946 & 0.876 \\
\hline \multirow{5}{*}{$\begin{array}{l}\text { Upper } \\
\text { leaf }\end{array}$} & $\mathrm{T} 1$ & $19.393 \pm 0.094 \mathrm{~A}$ & $20.201 \pm 0.060 \mathrm{~A}$ & $4.269 \pm 0.024 \mathrm{C}$ & $0.323 \pm 0.002 \mathrm{D}$ & $1.706 \pm 0.019 \mathrm{~A}$ \\
\hline & $\mathrm{T} 2$ & $21.127 \pm 0.159 \mathrm{~B}$ & $24.108 \pm 0.082 \mathrm{~B}$ & $3.892 \pm 0.009 \mathrm{~B}$ & $0.304 \pm 0.005 \mathrm{C}$ & $1.889 \pm 0.011 \mathrm{~B}$ \\
\hline & $\mathrm{T} 3$ & $22.960 \pm 0.041 \mathrm{C}$ & $26.028 \pm 0.068 \mathrm{C}$ & $3.908 \pm 0.011 \mathrm{~B}$ & $0.260 \pm 0.004 \mathrm{~B}$ & $1.912 \pm 0.008 \mathrm{~B}$ \\
\hline & $\mathrm{T} 4$ & $22.762 \pm 0.022 \mathrm{C}$ & $26.759 \pm 0.017 \mathrm{C}$ & $3.589 \pm 0.012 \mathrm{~A}$ & $0.240 \pm 0.004 \mathrm{~A}$ & $2.065 \pm 0.052 \mathrm{C}$ \\
\hline & leaf width/length ratio & 0.946 & $0.962^{*}$ & -0.934 & $-0.988^{*}$ & $0.961^{*}$ \\
\hline
\end{tabular}

Table 2. Effects of different leaf width/length ratio on coordination of chemical composition of leaf, and the correlation between leaf width/length ration and TS-RS, RS/TS, RS/Nic., K/Cl.

\begin{tabular}{|c|c|c|c|c|c|}
\hline Treatme & & $\mathrm{TS}^{\mathrm{RS}} \mathrm{S}^{\phi}$ & $\mathrm{RS} / \mathrm{TS}^{\mathrm{J}}$ & RS/Nic. ${ }^{\S}$ & $\mathrm{K} / \mathrm{Cl}^{\#}$ \\
\hline \multirow{5}{*}{$\begin{array}{l}\text { Middle } \\
\text { leaf }\end{array}$} & $\mathrm{T} 1$ & $5.945 \mathrm{~A}$ & $0.795 \mathrm{~B}$ & $7.836 \mathrm{~A}$ & $7.295 \mathrm{~A}$ \\
\hline & $\mathrm{T} 2$ & $6.247 \mathrm{~B}$ & $0.805 \mathrm{C}$ & $8.852 \mathrm{~B}$ & $8.934 \mathrm{~B}$ \\
\hline & $\mathrm{T} 3$ & $7.411 \mathrm{C}$ & $0.780 \mathrm{~A}$ & $9.440 \mathrm{C}$ & $9.065 \mathrm{~B}$ \\
\hline & $\mathrm{T} 4$ & $7.425 \mathrm{D}$ & $0.785 \mathrm{~A}$ & $11.051 \mathrm{D}$ & $10.490 \mathrm{C}$ \\
\hline & leaf width/length ratio & 0.936 & -0.640 & $0.982^{*}$ & $0.960^{*}$ \\
\hline \multirow{5}{*}{$\begin{array}{l}\text { Upper } \\
\text { leaf }\end{array}$} & $\mathrm{T} 1$ & $0.808 \mathrm{~A}$ & $0.960 \mathrm{C}$ & $4.543 \mathrm{~A}$ & $5.787 \mathrm{~A}$ \\
\hline & $\mathrm{T} 2$ & $2.981 \mathrm{~B}$ & $0.876 \mathrm{~B}$ & $5.428 \mathrm{~B}$ & $6.077 \mathrm{~A}$ \\
\hline & $\mathrm{T} 3$ & $3.068 \mathrm{~B}$ & $0.882 \mathrm{~B}$ & $5.875 \mathrm{C}$ & $7.473 \mathrm{~B}$ \\
\hline & $\mathrm{T} 4$ & $3.997 \mathrm{C}$ & $0.851 \mathrm{~A}$ & $6.342 \mathrm{D}$ & $8.939 \mathrm{C}$ \\
\hline & leaf width/length ratio & 0.928 & -0.886 & $0.989^{*}$ & $0.957^{*}$ \\
\hline
\end{tabular}

Note: Different capital letters stand for significant difference at 0.01 levels. " Significance at the $\mathrm{P} \leq 0.05$ level. ${ }^{\phi} T S-R S$ : the difference between the total and reducing sugar contents. ${ }^{\top} R S / T S$ : the ratio of reducing sugar to total sugar. ${ }^{\S} \mathrm{RS} / \mathrm{Nic}$ : the ratio of reducing sugar to nicotine. ${ }^{*} \mathrm{~K} / \mathrm{Cl}$ : the ratio of potassium to chlorine. $\boldsymbol{\nabla}$ : "Having a look at coefficient of correlation, all values look quite high and significant. If so, then they must be asterisked as well." The coefficient correlation look quite high, but did not reach significant levels by pearson. So do not add asterisked.

Table 3. Effects of different leaf width/length ratio on neutral aroma component content of flue-cured tobacco

\begin{tabular}{|c|c|c|c|c|c|c|c|c|}
\hline \multirow{2}{*}{ Neutral aroma component } & \multicolumn{4}{|l|}{ Middle leaf } & \multicolumn{4}{|l|}{ Upper leaf } \\
\hline & $\mathrm{T} 1$ & $\mathrm{~T} 2$ & $\mathrm{~T} 3$ & $\mathrm{~T} 4$ & $\mathrm{~T} 1$ & $\mathrm{~T} 2$ & $\mathrm{~T} 3$ & $\mathrm{~T} 4$ \\
\hline Phenylalanines & $2.654 \mathrm{~B}$ & $2.140 \mathrm{~A}$ & $4.405 \mathrm{C}$ & $5.528 \mathrm{D}$ & $4.294 \mathrm{~A}$ & $10.609 \mathrm{D}$ & $7.352 \mathrm{~B}$ & $7.573 \mathrm{C}$ \\
\hline Benzaldehyde & $0.180 \mathrm{~B}$ & $0.153 \mathrm{~A}$ & $0.159 \mathrm{~A}$ & $0.179 \mathrm{~B}$ & $0.192 \mathrm{~A}$ & $0.269 \mathrm{C}$ & $0.273 \mathrm{C}$ & $0.233 \mathrm{~B}$ \\
\hline Benzil alcohol & $1.053 \mathrm{~A}$ & $1.113 \mathrm{~B}$ & $2.356 \mathrm{D}$ & $2.289 \mathrm{C}$ & $1.709 \mathrm{~A}$ & $3.816 \mathrm{C}$ & $3.597 \mathrm{~B}$ & $4.172 \mathrm{D}$ \\
\hline Phenethyl ethyl alcohol & / & l & 0.738 & 0.770 & $0.843 \mathrm{~A}$ & $1.828 \mathrm{D}$ & $1.181 \mathrm{~B}$ & $1.374 \mathrm{C}$ \\
\hline Phenyl acetaldehyde & $1.421 \mathrm{C}$ & $0.874 \mathrm{~A}$ & $1.152 \mathrm{~B}$ & $2.289 \mathrm{D}$ & $1.550 \mathrm{~A}$ & $4.697 \mathrm{D}$ & $2.301 \mathrm{C}$ & $1.794 \mathrm{~B}$ \\
\hline Maillard reaction products & $18.756 \mathrm{~A}$ & $20.186 \mathrm{~B}$ & $23.014 \mathrm{C}$ & $20.060 \mathrm{D}$ & $24.330 \mathrm{~A}$ & $28.270 \mathrm{~B}$ & $29.286 \mathrm{C}$ & $32.734 \mathrm{D}$ \\
\hline Furfural & $15.548 \mathrm{~A}$ & $17.042 \mathrm{C}$ & $18.959 \mathrm{D}$ & $16.716 \mathrm{~B}$ & $19.365 \mathrm{~A}$ & $21.860 \mathrm{~B}$ & $22.731 \mathrm{C}$ & $25.629 \mathrm{D}$ \\
\hline 6-methyl-5-heptene-2-one & $0.342 \mathrm{D}$ & $0.224 \mathrm{~A}$ & $0.287 \mathrm{C}$ & $0.277 \mathrm{~B}$ & $0.322 \mathrm{~A}$ & $0.350 \mathrm{~B}$ & $0.402 \mathrm{D}$ & $0.365 \mathrm{C}$ \\
\hline 5-hydroxymethylfurfural & $1.100 \mathrm{~B}$ & $1.037 \mathrm{~A}$ & $1.267 \mathrm{D}$ & $1.208 \mathrm{C}$ & $1.760 \mathrm{~A}$ & $2.839 \mathrm{D}$ & $2.339 \mathrm{~B}$ & $2.458 \mathrm{C}$ \\
\hline 3,4-dimethyl-2,5-furandione & $0.220 \mathrm{~A}$ & $0.225 \mathrm{~A}$ & $0.625 \mathrm{C}$ & $0.365 \mathrm{D}$ & $0.577 \mathrm{~A}$ & $0.879 \mathrm{~B}$ & $0.939 \mathrm{C}$ & $1.206 \mathrm{D}$ \\
\hline 6-methyl-5-heptene-2-alcohol & $1.162 \mathrm{~B}$ & $1.203 \mathrm{C}$ & $1.358 \mathrm{D}$ & $1.106 \mathrm{~A}$ & $1.851 \mathrm{~A}$ & $1.928 \mathrm{~B}$ & $2.474 \mathrm{C}$ & $2.531 \mathrm{D}$ \\
\hline 2-acetylfuran & $0.385 \mathrm{~A}$ & $0.455 \mathrm{~B}$ & $0.518 \mathrm{C}$ & $0.390 \mathrm{~A}$ & $0.455 \mathrm{C}$ & $0.413 \mathrm{~B}$ & $0.401 \mathrm{~A}$ & $0.545 \mathrm{D}$ \\
\hline Cembranoids & $46.403 \mathrm{C}$ & $45.338 \mathrm{~B}$ & $53.550 \mathrm{D}$ & $38.474 \mathrm{~A}$ & $62.514 \mathrm{~B}$ & $55.378 \mathrm{~A}$ & $79.439 \mathrm{D}$ & $70.268 \mathrm{C}$ \\
\hline Solanone & $46.403 \mathrm{C}$ & $45.338 \mathrm{~B}$ & $53.550 \mathrm{D}$ & $38.474 \mathrm{~A}$ & $62.514 \mathrm{~B}$ & $55.378 \mathrm{~A}$ & $79.439 \mathrm{D}$ & $70.268 \mathrm{C}$ \\
\hline Carotenoids & $46.527 \mathrm{~A}$ & $46.511 \mathrm{~A}$ & $49.645 \mathrm{~B}$ & $53.366 \mathrm{C}$ & $52.835 \mathrm{~A}$ & $59.605 \mathrm{~B}$ & $119.414 \mathrm{D}$ & $61.251 \mathrm{C}$ \\
\hline$\beta$-damascenone & $18.929 \mathrm{~B}$ & $18.426 \mathrm{~A}$ & $19.074 \mathrm{C}$ & $19.644 \mathrm{D}$ & $19.318 \mathrm{~B}$ & $17.032 \mathrm{~A}$ & $78.519 \mathrm{D}$ & $19.945 \mathrm{C}$ \\
\hline Geranyl acetone & $0.917 \mathrm{~B}$ & $0.882 \mathrm{~A}$ & $1.093 \mathrm{C}$ & $1.210 \mathrm{D}$ & $1.284 \mathrm{~A}$ & $1.583 \mathrm{D}$ & $1.330 \mathrm{C}$ & $1.316 \mathrm{~B}$ \\
\hline Megastigmatrienone 1 & $1.293 \mathrm{C}$ & $1.165 \mathrm{~B}$ & $1.149 \mathrm{~A}$ & $1.420 \mathrm{D}$ & $1.432 \mathrm{~A}$ & $1.929 \mathrm{C}$ & $1.567 \mathrm{~B}$ & $1.428 \mathrm{~A}$ \\
\hline Megastigmatrienone 2 & $6.062 \mathrm{~B}$ & $5.706 \mathrm{~A}$ & $6.225 \mathrm{C}$ & $7.346 \mathrm{D}$ & $6.325 \mathrm{~A}$ & $8.738 \mathrm{D}$ & $6.479 \mathrm{~B}$ & $7.017 \mathrm{C}$ \\
\hline Megastigmatrienone 3 & $3.135 \mathrm{C}$ & $3.303 \mathrm{D}$ & $3.091 \mathrm{~B}$ & $2.446 \mathrm{~A}$ & $5.169 \mathrm{~A}$ & $5.748 \mathrm{~B}$ & $8.586 \mathrm{D}$ & $6.754 \mathrm{C}$ \\
\hline Megastigmatrienone 4 & $7.189 \mathrm{~A}$ & $7.452 \mathrm{~B}$ & $8.553 \mathrm{C}$ & $9.784 \mathrm{D}$ & $8.223 \mathrm{~A}$ & $10.886 \mathrm{D}$ & $9.604 \mathrm{~B}$ & $10.644 \mathrm{C}$ \\
\hline Farnesyl acetone & $5.693 \mathrm{~A}$ & $6.219 \mathrm{~B}$ & $6.396 \mathrm{C}$ & $7.490 \mathrm{D}$ & $6.770 \mathrm{~A}$ & $8.275 \mathrm{D}$ & $7.832 \mathrm{~B}$ & $7.870 \mathrm{C}$ \\
\hline Screw vetiver ketone & $0.684 \mathrm{~B}$ & $0.564 \mathrm{~A}$ & $0.785 \mathrm{D}$ & $0.762 \mathrm{C}$ & $0.694 \mathrm{~A}$ & $0.942 \mathrm{~B}$ & $1.012 \mathrm{C}$ & $1.206 \mathrm{D}$ \\
\hline Linalool & $0.448 \mathrm{~A}$ & $0.483 \mathrm{~A}$ & $0.511 \mathrm{~A}$ & $0.532 \mathrm{~A}$ & $0.597 \mathrm{~B}$ & $0.582 \mathrm{~A}$ & $0.623 \mathrm{C}$ & $0.712 \mathrm{D}$ \\
\hline 3-hydroxy- $\beta$-dimascone & $1.408 \mathrm{~A}$ & $1.377 \mathrm{~A}$ & $1.691 \mathrm{AB}$ & $1.856 \mathrm{~B}$ & $1.789 \mathrm{~A}$ & $2.248 \mathrm{D}$ & $2.064 \mathrm{C}$ & $2.038 \mathrm{~B}$ \\
\hline Dihydroactinidiolide & $0.772 \mathrm{~A}$ & $0.933 \mathrm{C}$ & $1.078 \mathrm{D}$ & $0.876 \mathrm{~B}$ & $1.235 \mathrm{~A}$ & $1.641 \mathrm{~B}$ & $1.799 \mathrm{C}$ & $2.321 \mathrm{D}$ \\
\hline Neophytadienes & $901.381 \mathrm{~A}$ & $953.770 \mathrm{~B}$ & $1147.000 \mathrm{C}$ & $1175.000 \mathrm{D}$ & $863.127 \mathrm{~A}$ & $957.502 \mathrm{~B}$ & $1031.000 \mathrm{C}$ & $1232.000 \mathrm{D}$ \\
\hline Other aroma substances & $3.491 \mathrm{~B}$ & $3.638 \mathrm{C}$ & $3.522 \mathrm{~B}$ & $3.168 \mathrm{~A}$ & $4.1483 \mathrm{~A}$ & $4.4268 \mathrm{~B}$ & $4.9455 \mathrm{D}$ & $4.4345 \mathrm{C}$ \\
\hline Oxidation of isophorone & 0.099 & 1 & I & 0.110 & / & 0.124 & 0.136 & 0.122 \\
\hline Guaiacol & $1.814 \mathrm{C}$ & $1.818 \mathrm{C}$ & $1.517 \mathrm{~B}$ & $1.479 \mathrm{~A}$ & $2.396 \mathrm{~B}$ & $2.720 \mathrm{D}$ & $2.495 \mathrm{C}$ & $2.191 \mathrm{~A}$ \\
\hline 2-methyltetrafuran-3-one & $0.225 \mathrm{~A}$ & $0.251 \mathrm{C}$ & $0.269 \mathrm{D}$ & $0.238 \mathrm{~B}$ & $0.269 \mathrm{~A}$ & $0.300 \mathrm{~B}$ & $0.349 \mathrm{C}$ & $0.364 \mathrm{D}$ \\
\hline Safranal & $0.151 \mathrm{~B}$ & $0.158 \mathrm{C}$ & $0.137 \mathrm{~A}$ & $0.149 \mathrm{~B}$ & $0.200 \mathrm{~A}$ & $0.250 \mathrm{~B}$ & $0.218 \mathrm{~A}$ & $0.209 \mathrm{~A}$ \\
\hline 2,6-Nonadienal & $0.475 \mathrm{~A}$ & $0.637 \mathrm{C}$ & $0.870 \mathrm{D}$ & $0.592 \mathrm{~B}$ & $0.490 \mathrm{C}$ & $0.269 \mathrm{~A}$ & $0.572 \mathrm{D}$ & $0.434 \mathrm{~B}$ \\
\hline$\beta$-Damascon & $0.727 \mathrm{~B}$ & $0.774 \mathrm{C}$ & $0.729 \mathrm{~B}$ & $0.600 \mathrm{~A}$ & $0.794 \mathrm{~B}$ & $0.764 \mathrm{~A}$ & $1.176 \mathrm{D}$ & $1.115 \mathrm{C}$ \\
\hline & 1019.212 & 1071.582 & 1281.136 & 1295.595 & 1011.248 & 1115.790 & & \\
\hline Total & A & $\mathrm{B}$ & $\mathrm{C}$ & $\mathrm{D}$ & A & B & $1271.436 \mathrm{C}$ & $1408.260 \mathrm{D}$ \\
\hline
\end{tabular}


Table 4. The leaf length and leaf breadth of different treatment.

\begin{tabular}{|c|c|c|c|c|}
\hline \multicolumn{2}{|c|}{ Treatments } & \multirow{2}{*}{$\frac{\text { Leaf length }(\mathrm{cm})}{75 \pm 1}$} & \multirow{2}{*}{$\begin{array}{c}\text { Leaf breadth }(\mathrm{cm}) \\
12 \pm 1 \mathrm{D}\end{array}$} & \multirow{2}{*}{$\begin{array}{c}\text { Leaf openness }(\%) \\
0.16 \pm 0.02 \mathrm{D}\end{array}$} \\
\hline & $\mathrm{T} 1$ & & & \\
\hline Middle & $\mathrm{T} 2$ & $75 \pm 1$ & $15 \pm 1 \mathrm{C}$ & $0.20 \pm 0.02 \mathrm{C}$ \\
\hline \multirow[t]{3}{*}{ leaf } & $\mathrm{T} 3$ & $75 \pm 1$ & $18 \pm 1 \mathrm{~B}$ & $0.24 \pm 0.02 \mathrm{~B}$ \\
\hline & $\mathrm{T} 4$ & $75 \pm 1$ & $21 \pm 1 \mathrm{~A}$ & $0.28 \pm 0.02 \mathrm{~A}$ \\
\hline & $\mathrm{T} 1$ & $65 \pm 1$ & $12 \pm 1 \mathrm{D}$ & $0.18 \pm 0.02 \mathrm{D}$ \\
\hline \multirow{3}{*}{$\begin{array}{l}\text { Upper } \\
\text { leaf }\end{array}$} & $\mathrm{T} 2$ & $65 \pm 1$ & $15 \pm 1 \mathrm{C}$ & $0.23 \pm 0.02 \mathrm{C}$ \\
\hline & $\mathrm{T} 3$ & $65 \pm 1$ & $18 \pm 1 \mathrm{~B}$ & $0.28 \pm 0.02 \mathrm{~B}$ \\
\hline & $\mathrm{T} 4$ & $65 \pm 1$ & $21 \pm 1 \mathrm{~A}$ & $0.32 \pm 0.02 \mathrm{~A}$ \\
\hline
\end{tabular}

meet the quality requirement for tobacco leaves. Meanwhile, the chlorine content, which could deteriorate the quality of tobacco leaves, became lower.

\section{Effects of leaf width/length ratio on the coordination of tobacco chemical composition}

Coordination of chemical composition is an important index for the evaluation of tobacco quality and an important factor for determining tobacco value for industrial use (Du et al., 2007). In this study, four coordination indices were used: the difference between total sugar and reducing sugar, ratio of reducing sugar to total sugar, ratio of sugar to nicotine, and ratio of potassium to chlorine. These indices were utilized to evaluate the effects of leaf width/length ratio on coordination of tobacco chemical composition (Table 2). As shown in Tables 1 and 2, the difference between the total and reducing sugar contents, the ratio of sugar to nicotine, and the ratio of potassium to chlorine increased with increasing leaf width/length ratio. In addition, significant differences were observed among different treatment groups. The leaf width/length ratio and the ratio of reducing sugar to total sugar showed a highly significant negative correlation.

The proportion of sugars in tobacco is closely related to the sensory quality of tobacco. Therefore, it is an important index for the evaluation of tobacco leaf quality (Chang et al., 2009). Research has shown that with increase in leaf width/length ratio of tobacco, its non-reducing sugar content and the difference between total and reducing sugar contents also increase gradually. By contrast, the ratio of reducing to total sugar contents decreases gradually. In other words, the coordination of sugar composition worsens with increasing leaf width/length ratio. This result may be due to the unappealing and scorching characteristics of tobacco. Furthermore, the irritation associated with increased tar content could increase, leading to decrease in safety (Wang, 2003). Next, coordination between sugar and nicotine as well as that between potassium and chlorine were analyzed. The results revealed that larger leaf width/length ratio correlated with a more harmonious composition of tobacco leaves. Thus, the larger leaf width/length ratio of tobacco is beneficial for satisfying the needs of high-quality tobacco production (Du et al., 2007).

\section{Effects of leaf width/length ratio on the contents of neutral aroma components}

Aroma components are essential factors for the analysis and discrimination of tobacco features (Yu, et al., 2006). In this study, aroma substances were classified into six categories, namely, phenylalanines, Maillard reaction products, cembranoids, carotenoids, neophytadiene, and other aroma substances (Liu et al., 2011). The results of our analyses for these six categories are shown in Table 3. As displayed, the contents of the neutral aroma components increased with increasing leaf width/length ratio. Aromatic phenylalanines significantly contribute to the fruity flavor and delicate fragrance of flue-cured tobacco (Shi et al., 1998). Benzil alcohol and phenethyl ethyl alcohol are the most important ingredients that promote the flower fragrance of smoke (Zhou et al., 2008). The differences in aromatic phenylalanine content among tobacco plants with different leaf width/length ratios were large. With increase in leaf width/length ratio, the contents of aromatic phenylalanines increased significantly. Similar variation trends were also found in the contents of benzil alcohol and phenethyl ethyl alcohol. These findings suggest that enhancement of flue-cured tobacco leaf width/length ratio in the Chongqing tobacco production area could improve the quality of the smell and the fruity flavor and flower fragrance of tobacco.

Maillard reaction is an important process involved in the formation of components of tobacco aroma. The reaction products can play roles in covering up impure odor, enhancing aroma and improving smoke quality (Shi et al., 1998). Table 4 shows that the Maillard reaction products were significantly affected by leaf width/length ratio. With increase in leaf width/length ratio, a gradually increasing trend in the contents of Maillard reaction products was observed. The content of furfural was the highest among the Maillard reaction products, followed by the contents of 5-methyl furfural and 6-methyl-5-hepten-2-alcohol. The contents of 6-methyl-5 -hepten-2-one, 2-acetylfuran and 3,4-dimethyl-2,5-furandione were lower. The contents of all of these components significantly increased with increasing leaf width/length ratio. Thus, increase in leaf width/length ratio could result in improved aromatic quality of tobacco smoke.

Carotenoids are important components contributing to tobacco aroma quality. Their degradation and pyrolysis products are the main aroma components that make flue-cured tobacco smooth, elegant, and fresh (Yang et al., 2005). As shown in Table 4, $\beta$-damascenone and megastigmatrienone were found to be the major carotenoid components of tobacco. Increasing trends in the contents of these components were observed with increasing leaf width/length ratio. The total amount of carotenoids also followed a similar trend.

Neophytadiene is generated by chlorophyll degradation and is the most abundant among the neutral aroma components of flue-cured tobacco (Zhou et al., 1996). Presence of this compound in smoke can help mitigate irritation and lessen smoke intensity. Moreover, the compound can be degraded and converted to plant furan, which possesses a delicate fragrance (Zhou et al., 2008). In this study, we found that with increasing leaf width/length ratio, the contents of neophytadiene of the upper and lower leaves increased significantly. The content of neophytadiene in the upper leaf was significantly affected by the leaf width/length ratio. Specifically, T4 increased by $42.74 \%$ relative to $\mathrm{T} 1$. T4 in the middle leaf only increased by $30.36 \%$ compared to $\mathrm{T} 1$. Under experimental conditions, only solanone was detected among the cembranoids (Table 4). As indicated by our data on the total contents of aromatic substances, increasing leaf width/length ratio significantly 
affected the enhancement of aromatic substances. The total contents of aromatic substances of upper and lower leaves followed the order $\mathrm{T} 4>\mathrm{T} 3>\mathrm{T} 2>\mathrm{T} 1$.

\section{Discussion}

In some flue-cured tobacco production areas in China, upper leaves are usually long and narrow because of insufficient development. This phenomenon is referred to as the "less lateral extension of leaf" in tobacco production. Such leaves typically suffer from high thickness, tight structure, high content of nicotine, and uncoordinated chemical composition. These problems result in lower yields of first- and middle-class cigarettes and poor usability of upper leaves (Yin, 2001). Thus, massive upper leaves are overstocked in China. In this study, the effects of leaf width/length ratio on tobacco leaf quality were investigated in detail.

Chemical ingredients are important indices for evaluating the quality of flue-cured tobacco leaf. These components can determine its sensory quality and smoke characteristics (Du et al., 2007). In addition, the balance and degree of coordination of chemical indices determine the industrial value of tobacco. In this study, we found that correlations of the contents of total sugar, reducing sugar, and potassium with the leaf width/length ratio were significantly positive. However, the correlations of the contents of nicotine and chlorine with the leaf width/length ratio were significantly negative. The leaf area with larger leaf width/length ratio was wider compared to other leaf areas. Hence, more photosynthesis products accumulated and their sugar contents were also higher. In addition, transpirational pull and potassium absorption were both stronger in leaves with large areas (Pan and Dong, 1995). This effect may explain the higher potassium content of tobacco leaves with larger leaf width/length ratio. However, the reasons for lower chlorine and nicotine contents of leaves with larger leaf width/length ratio must be investigated further.

Leaf width/length ratio significantly affects the coordination of leaf chemical composition. Our results showed that increase in leaf width/length ratio increased the difference between total and reducing sugar contents, the ratio of sugar to nicotine, and the ratio of potassium to chlorine. Moreover, the non-reducing sugar content increased. These findings indicate that coordination of sugar composition became poorer with increase in leaf width/length ratio. Poor sugar composition can cause the smoke to become insipid and scorching. Moreover, smoke-induced irritation could increase with increased tar content, making tobacco smoke less safe (Wang, 2003). Thus, increasing the leaf width/length ratio promoted the coordination between sugars and nicotine as well as that between potassium and chlorine, thereby improving tobacco quality (Du et al., 2007).

Aroma is an important index for tobacco quality evaluation. To some extent, tobacco quality depends on the composition of leaf aroma components (Zhou et al., 2008). The composition of aroma components is significantly affected by factors such as genetics (Zhao et al., 2008), environment (Zhang et al., 2012), and cultivation method (Han et al., 2012). This work revealed that the contents of neutral aroma components are largely affected by leaf width/length ratio. The contents of phenylalanines, Maillard reaction products, carotenoids, and neophytadiene increased significantly with increase in leaf width/length ratio. The increase was particularly large for benzil alcohol, phenethyl ethyl alcohol, furfural, $\beta$-damascenone, and megastigmatrienone. This might be related to larger photosynthetic area of leaves with larger leaf width/length ratio, which causes greater accumulation of photosynthetic products and increased formation of aroma substance precursors. Hence, increasing the tobacco leaf width/length ratio is likely beneficial for mitigating irritation associated with smoking, softening the smoke (Shi and Liu, 1998), as well as improving aroma quality, enhancing flower fragrance and fruity flavor (Shi and Liu, 1998; Zhou et al., 2008), and promoting the development of elegant fragrance in tobacco smoke (Yang et al., 2005). Given the relationship between the total contents of neutral aroma substances of the upper and lower leaves and the leaf width/length ratio, we infer that with increase in leaf width/length ratio, the total contents of neutral aroma substances in the upper and middle leaves continuously increased in the order $\mathrm{T} 4>\mathrm{T} 3>\mathrm{T} 2>\mathrm{T} 1$. Leaves with larger leaf width/length ratios could better coordinate hydrocarbon metabolism, which could in turn promote degradation of neutral aroma precursors. Taken together, our results indicate that higher leaf width/length ratio leads to increase in the number of neutral aroma substances, thereby improving tobacco leaf quality.

\section{Materials and methods}

\section{Experimental materials}

Experiments were carried out in tobacco fields with equal soil fertility in six major tobacco production areas of Chongqing in 2014. The Yunyan 87 breed of tobacco was planted, and plants that grew well were selected for leaf analysis. The ninth to tenth leaves were designated as the middle leaves, whereas the $15^{\text {th }}$ and $16^{\text {th }}$ leaves were marked as the upper leaves at the topping stage. After harvesting and curing the mature tobacco leaves, we selected leaves of grades C3F and B2F. The weight of each sample was $4 \mathrm{~kg}$. Samples from different places of origin were mixed separately for each grade. The samples were then treated and sorted in accordance with Table 4. The experiment was designed with four treatment conditions. The leaf widths were 12 (T1), 15 (T2), 18 (T3), and 21 (T4) cm, while the leaf lengths were 75 and $65 \mathrm{~cm}$ for the middle and upper leaves, respectively. Three replicates were used for each treatment condition.

\section{Sample measurements and data analysis}

Chemical ingredients of the tobacco samples were tested using a continuous flow analyzer. Neutral aroma components were tested by the internal standard method (nitrobenzene) using a gas chromatograph-mass spectrometer. ANOVA was employed to analyze data using SPSS 19.0. Leaf openness was defined as the leaf width/length ratio, which has been used previously to evaluate the development status of flue-cured tobacco leaves (Liu, et al., 2012).

\section{Conclusions}

In this study, we investigated the effects of width/length ratio of the upper and middle leaves of "Yunyan 87" on leaf chemical ingredients and contents of neutral aroma substances. Results showed that the correlations between leaf width/length ratio and contents of total sugar, reducing sugar, and potassium in the upper and middle leaves were significantly positive. By contrast, the correlations between leaf width/length ratio and contents of nicotine and chlorine were significantly negative. With increase in leaf width/length ratio, the difference between total and reducing sugar contents, the ratio of sugar to nicotine, and the ratio of potassium to chlorine increased, whereas the ratio of reducing to total sugar decreased. Meanwhile, the contents of phenylalanines, Maillard reaction products, carotenoids, and neophytadiene obviously improved. The 
contents of neutral aroma substances also increased. Therefore, appropriate measures should be implemented during tobacco production in the Chongqing tobacco production area to enhance the width/length ratio of upper and middle leaves in order to improve tobacco leaf quality.

\section{Acknowledgements}

The authors thank the Chongqing Tobacco Company for funding this research (Projects number: NY20150601070011). The authors also thank Shen Zheng, Wang Zhijian, Wang Hongye, Li Huachuan for their assistance in sampling flue-cured tobacco seedlings.

\section{Conferences}

Chang AX, Du YM, Fu QJ, Niu BQ, Wang SS, Liu HX, Wen L, Tan QT, Liu Y (2009) Correlationship between main chemical components and sensory quality of flue-cured tobacco. ChinTob Sci. 30(6):9-12.

Chen JH, Liu JL, Long HY (2004) The distribution characteristics of nutrition elements and main chemical composition in China's tobacco leaves. Acta Tab Sin. 10(5):20-27.

Cheng S, Tang Y, Gong CR, Dou YQ, Yang P, Yang ZL, Xue LB, Li C (2007) Study on the leaf properties and curing characteristics of flue-cured tobacco leaves in Damianshan. ChinTob Sci. 28(2):31-37.

Du W, Tan XL, Yi JH, Su QD (2007) Evaluation of leaf tobacco quality using chemical composition data. Acta Tab Sin. 13(3):25-31.

Han FG, Wang H, Wang LC, Kang XL (2012) Effects of different water-fertilizer conditions and harvest time on aroma quality of flue-cured tobacco. J Henan Agric Univ. 46(1):22-25.

Liu GS, Jiang HL, Liu SD, Yang YF, Hu HC, Liu QH (2011) Identifying management zones in tobacco-planted fields based on tobacco quality. Plant Nutr Fert Sci. 17(4):1028-1035.
Liu Y, Zhou JH, Zhou GS, Liu YQ, Fang M, Mao ZP, and Liu J (2012) Effects of harvesting method and maturity on yield-quality of upper leaves of flue-cured tobacco. Acta Agric Univ Jiangxiensis (Nat Sci Edn.). 34(1):16-21.

Pan RZ, Dong YD (1995) Plant physiology. Beijing: Chin. High. Edu. Press.

Wang RX (2003) Tobacco chemistry. Beijing: Chin Agric Press.

Shi HZ, Liu GS (1998) Tobacco aroma science. Beijing: Chin. Agric Press.

Xu ZC, Liu GS, Liu JH, Jin WH, Shi SC, Niu DJ, Zhu ZY (2005) Analysis of ecological factors and quality of flue-cured tobacco leaves in Tongshan tobacco-growing areas. Acta Ecol Sin. 25(7):1748-1753.

Yang HQ, Zhou JH, Yang SY, Wang Y, Zhou QM, Luo ZM (2005) Effect on chiefly latent fragrant substance on panel test flue-cured tobacco from different producing area. J Hunan AgricUniv. (Nat Sci.). 31(1):11-14.

Yan KY, Yuan ZY, Wu DX, Li XB, Qu JB (2001) Study on the evaluating index system for quality of flue-cured tobacco. J Zhengzhou Inst Light Ind. 16(12):57-61.

Yin GS, Lin GP, Tang JX, Wei YJ (2001) The correlation among main agronomic characters and their effects on economic indexes of flue-cured tobacco by the grey incidence analysis. Tobacco Sci Tech. (1): 38-40.

Yu JJ, Pang TH, Ren XH, Li L, Dai HJ, Li AJ (2006) Research on relationship between neutral aroma constituents and smoking quality in flue-cured tobacco. J Henan Agric Univ. 40(4):346-349.

Zhang Q, Dong GF, He ZJ, Xiang M, Tian LM, Li HW (2012) Analysis of difference in neutral aroma components of flue-cured tobacco in main tobacco-growing areas in Yunnan province. Acta Agric Jiangxi. 24(7):80-84.

Zhao MQ, Li XQ, Han J, Zhao YZ (2008) Study on neutral aroma constituent contents in different genotypes of flue-cured tobacco. Acta Tab Sin. 14(3):46-51.

Zhou JH, Zhu XP, Wang YT, Liu GS, Zhang MN (1996) Physiology and biochemistry of tobacco. Hefei Univ Sci Tech. Chin. Press, 89-145, 481.

Zhou K, Zhou QM, Hu XL (2008) Advance in aroma substances in flue-cured tobacco. ChinTob Sci. 29(2):58-61.

Zuo TJ (1993) Production, physiology and biochemistry of tobacco [M]. Shanghai: Shanghai Far-east Publishers. 